\title{
Coverage for SC genomes
}

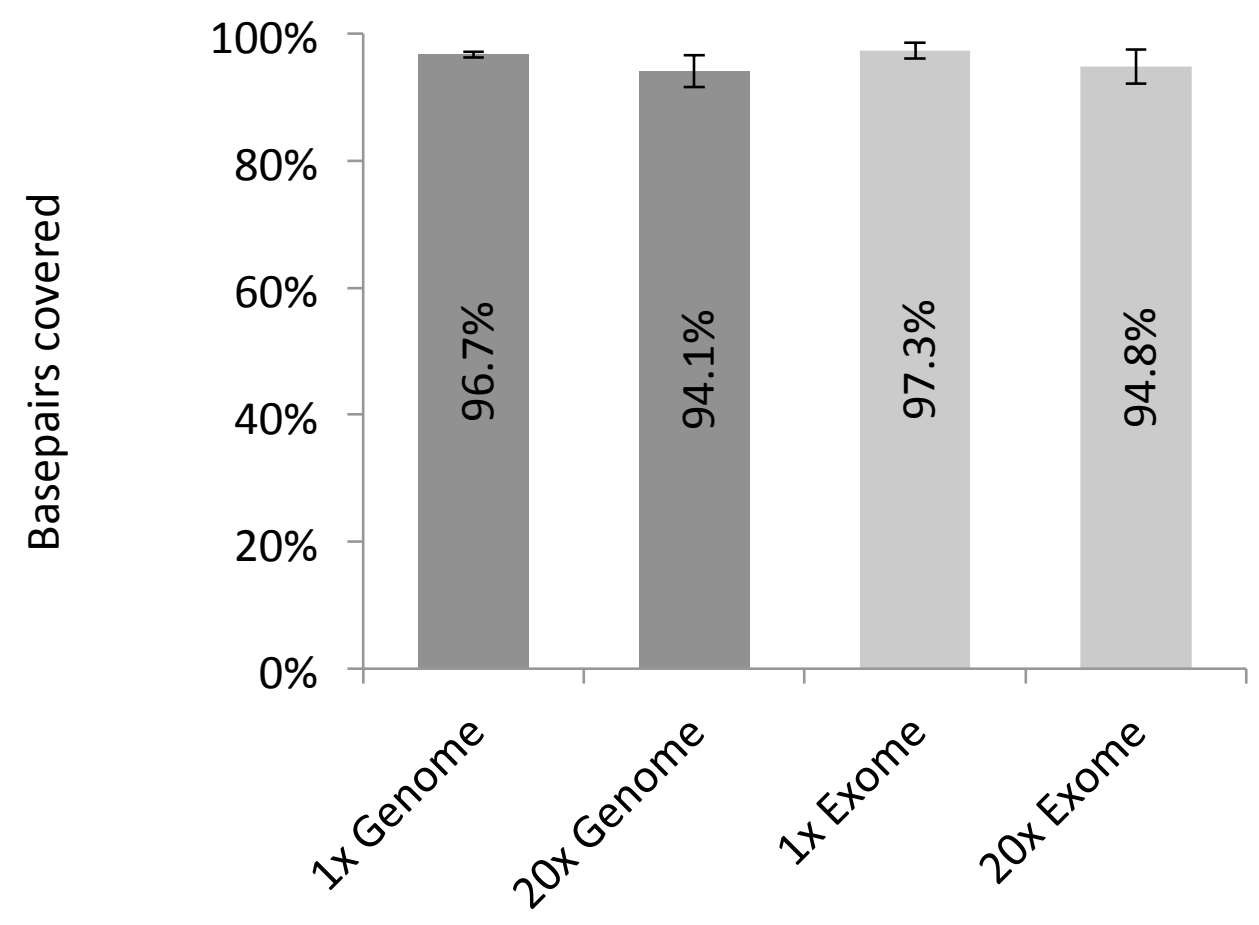

Figure S1 Genome coverage for supercentenarians. Average genome coverage is shown for the whole genome (dark grey) and exome (light grey) of all 17 supercentenarians. Coverage is shown for $\geq 1 \mathrm{x}$ and $\geq 20 \mathrm{x}$ coverage. 